2018

\title{
Integrated Ocean, Earth, and Atmospheric Observations for Resilience Planning in Hampton Roads, Virginia
}

Jon Derek Loftis

College of William \& Mary

Molly Mitchell

College of William \& Mary

Larry Atkinson

Old Dominion University, latkinso@odu.edu

Ben Hamlington

Old Dominion University, bhamling@odu.edu

Tom Allen

Old Dominion University, tallen@odu.edu

See next page for additional authors

Follow this and additional works at: https://digitalcommons.odu.edu/ccpo_pubs

Part of the Environmental Sciences Commons, Hydrology Commons, and the Oceanography and Atmospheric Sciences and Meteorology Commons

\section{Repository Citation}

Loftis, Jon Derek; Mitchell, Molly; Atkinson, Larry; Hamlington, Ben; Allen, Tom; Forrest, David; Updyke, Teresa; Tahvildari, Navid; Bekaert, David; and Bushnell, Mark, "Integrated Ocean, Earth, and Atmospheric Observations for Resilience Planning in Hampton Roads, Virginia" (2018). CCPO Publications. 251.

https://digitalcommons.odu.edu/ccpo_pubs/251

\section{Original Publication Citation}

Loftis, J. D., Mitchell, M., Atkinson, L., Hamlington, B., Allen, T. R., Forrest, D., .. Bushnell, M. (2018). Integrated ocean, earth, and atmospheric observations for resilience planning in Hampton Roads, Virginia. Marine Technology Society Journal, 52(2), 68-83. doi:10.4031/MTSJ.52.2.8 
Authors

Jon Derek Loftis, Molly Mitchell, Larry Atkinson, Ben Hamlington, Tom Allen, David Forrest, Teresa Updyke, Navid Tahvildari, David Bekaert, and Mark Bushnell 


\section{Integrated Ocean, Earth, and Atmospheric Observations for Resilience Planning in Hampton Roads, Virginia}

\section{A UTHORS}

\section{Jon Derek Loftis}

Molly Mitchell

Center for Coastal Resources

Management, Virginia Institute

of Marine Science,

College of William \& Mary

\section{Larry Atkinson}

Ben Hamlington

Center for Coastal Physical

Oceanography, Old Dominion

University

\section{Thomas R. Allen}

Department of Political

Science and Geography,

Old Dominion University

\section{David Forrest}

Department of Physical Sciences,

Virginia Institute of Marine Science,

College of William \& Mary

Teresa Updyke

Center for Coastal Physical

Oceanography, Old Dominion

University

\section{Navid Tahvildari}

Department of Civil and

Environmental Engineering,

Old Dominion University

\section{David Bekaert}

Jet Propulsion Laboratory, California Institute of Technology

Mark Bushnell

CoastalObsTechServices LLC, Virginia Beach, Virginia

\section{A B S T R A C T}

Building flood resilience in coastal communities requires a precise understanding of the temporal and spatial scales of inundation and the ability to detect and predict changes in flooding. In Hampton Roads, the Intergovernmental Pilot Project's Scientific Advisory Committee recommended an integrated network of ocean, earth, and atmospheric data collection from both private and public sector organizations that engage in active scientific monitoring and observing. Since its establishment, the network has grown to include monitoring of water levels, land subsidence, wave measurements, current measurements, and atmospheric conditions. High-resolution land elevation and land cover data sets have also been developed. These products have been incorporated into a number of portals and integrated tools to help support resilience planning. Significant challenges to building the network included establishing consistent data standards across organizations to allow for the integration of the data into multiple, unique products and funding the expansion of the network components. Recommendations to the network development in Hampton Roads include the need to continue to support and expand the publicly available network of sensors; enhance integration between ocean, earth, and atmospheric networks; and improve shallow water bathymetry data used in spatial flooding models.

Keywords: sensor, flood, water level, monitoring, StormSense

\section{Introduction}

he Hampton Roads, Virginia,
area has experienced increasing vul-
nerability to flooding due to high
rates of relative sea level rise (Ezer \&
Atkinson, 2014) and a long history
of human waterfront settlement. For
many years, flood management strat-
egy has focused on reducing vulner-
abilities by addressing impacted
infrastructure while maintaining the
status quo (i.e., elevating houses to
prevent flood damage but still allow-
ing people to live in the same places).
However, the rising social and eco-

nomic costs from increased flood frequency and the recognition that sea level rise will exacerbate these costs (Boon \& Mitchell, 2015) have led to the understanding that the government needs to address regional resilience, rather than continue with the ad hoc patching of vulnerabilities.

A key component of resiliency planning is the recognition that management strategies should address the nonlinear nature of changing systems as well as the inherent uncertainty in our understanding of it (Folke, 2006). Effectively incorporating predictions 
of near-term and future flooding with mitigating strategies into resiliency planning requires a precise understanding of the temporal and spatial scales of current flooding, coastal dynamics, and precipitation patterns (Boon et al., 2018). This level of detail allows for an inventory of infrastructure currently at risk, the development of flood early warning systems (reducing current vulnerabilities) and high-resolution hydrodynamic models (increasing our resilience to future storm surge and sea level rise), and improved predictions of future risk.

Collaborative planning is critical in areas (such as Hampton Roads) where flood-prone regions cross jurisdictional boundaries. Locality-specific adoption of different strategies can lead to a coastline without cohesive protection measures and where the failure of protection measures in one community may impact the success of protection measures in an adjacent community. Collaborative planning efforts require cooperation on multiple levels, including the generation of seamless data sets. In Hampton Roads, the Intergovernmental Pilot Project (IPP; http://digitalcommons. odu.edu/odurc_pilot/) was established to coordinate a "whole of government" approach to regional resiliency planning (Toll, 2018). Their three key recommendations were (1) to establish, maintain, and institutionalize relationships to support collaboration and information sharing; (2) to standardize methods for integrating and sharing data; and (3) to apply the "Whole of Government and Community" approach to the watershed level as opposed to jurisdictional boundaries (Steinhilber et al., 2016).

Within the IPP, a Scientific Advisory Committee (SAC) comprising representatives from both private and public sector organizations engaged in a review of active scientific monitoring and observing within the Hampton Roads area. This committee is responsible for ensuring that member organizations work together to integrate a network of ocean, earth, and atmospheric data collection. This network includes private companies; academic institutions; and local, state, and federal government organizations. Although the IPP's efforts have technically been concluded, integrated collaborations on this issue continue under three main initiatives, including the following:

1. the Commonwealth Center for Recurrent Flooding Resiliency (CCRFR; http://www.flooding resiliency.org/), a state-funded virtual research center established between the Virginia Institute of Marine Science (VIMS), the Old Dominion University, and the Virginia Coastal Policy Center at the William and Mary Law School and serves as a source of scientific, socioeconomic, legal, and policy analyses aimed at building Virginia's resiliency against flooding;

2. the Climate Change and Sea Level Rise Initiative and Old Dominion University's Resilience Collaborative (http://www.odu.edu/impact/ initiatives/resiliencecollaborative); and

3. the Hampton Roads Adaptation Forum supported by Virginia Sea Grant and the Hampton Roads Planning District Commission (https://sites.wp.odu.edu/ HRAdaptationForum/). Between these groups and the region, the key challenge in the collaboration, thus far, has been to ensure that data standards are consistent across organizations to allow for the integration of the data into multiple products with unique management focuses. In this paper, we document all the publicly available environmental observations in the region and the resulting models and portals for efforts to integrating the observations into formats useful for resiliency planning.

\section{Observation Networks and Integration}

Many different companies, academic institutions, federal, commonwealth, and city governments make environmental observations in the region. There is also much collaboration between these organizations to facilitate dissemination and archiving of the data. The main types of observations are water level, subsidence, topographic, wave/current measurements, and weather observations. All of these observations are critical for the modeling of past and future precipitationand wave-driven flood impacts that feed into resilience planning. Coverage of the different observation systems varies, creating unique challenges for the integration of the data into robust tools. The extent and format of each observing system are described in this section. In addition, nascent efforts to develop citizen science observations are ongoing, including a recent crowdsourcing effort using a mobile application developed in Norfolk called "sea level rise" to measure a king tide event in early November 2017. Sponsored by the nonprofit Wetlands Watch and promoted by the regional Virginian-Pilot newspaper, among other media partners, the "Catch the King" event portends increased awareness and potential scientific observations from 
the community that could prove valuable to mapping and model validation as well as public awareness (Loftis, 2017). This section's subsections outline all known available observations for (1) water level, (2) subsidence, (3) elevations, (4) waves, (5) currents, (6) atmospheric data, and (7) Gulf Stream dynamics.

\section{Water Level Observations}

There are many different types of sensors that provide different utilities of value, depending on particular focus for measuring water level extremes. Water level sensors directly report the water elevations using a standard vertical datum above the North American Vertical Datum of 1988 (NAVD88) or mean sea level (MSL). By default, the National Oceanic and Atmospheric Administration (NOAA) reports these water levels relative to MSL with numerous other tidal and geodetic datum options, whereas the U.S. Geological Survey (USGS) exclusively reports their levels relative to NAVD88, with both reporting water levels every $6 \mathrm{~min}$. Water levels are presently publicly monitored in 57 locations throughout the region by NOAA, USGS, VIMS, WeatherFlow, and StormSense, each comprising 6, 19, 1, 3, and 28 sensors in their respective portfolios (Figure 1). There also exist nonpublic sensor data collected by cities, which are somewhat limited for dissemination due to aging Supervisory Control And Data Acquisition (SCADA) architecture or limited communications functions. NOAA, the National Weather Service (NWS), and Tidewatch provide tide predictions at some of these gauges.

The National Ocean Service (NOS) of NOAA provides the most long-term and accurate water level

\section{FIGURE 1}

Map of 56 publicly streaming water level monitoring stations throughout Hampton Roads, VA. Among federal entities, NOAA has six (marked in blue), and USGS maintains 19 (noted in green), whereas among local entities, VIMS has one, WeatherFlow has three, and StormSense has 28 (all marked in red). Click Figure or http://arcg.is/14aCe1 for interactive station map.

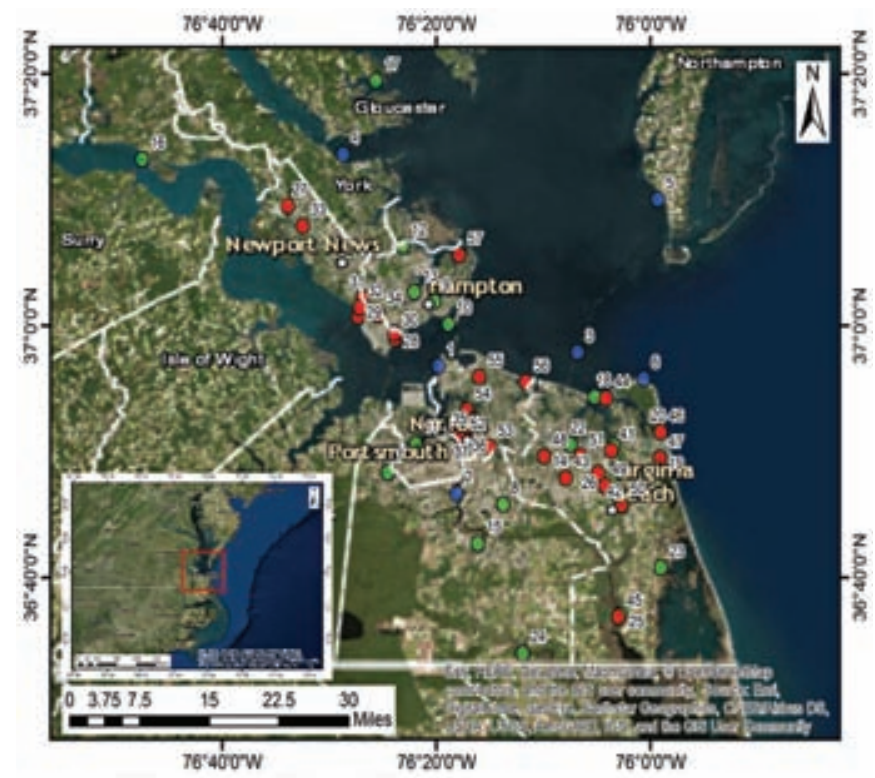

observations. More recently, USGS and regional cities have installed more gauges. Most water level sensors in Hampton Roads are mounted to piers over open waterways or in sheltered marinas, as these sites accommodate a broad range of water level measurements from very low water events along with high water flood events. However, there are also inundation sensors in use, such as the temporary battery-powered rapid deployment gauges the USGS deploys in advance of substantial flood events over land or the new ultrasonic street inundation sensors the City of Norfolk installed as part of the StormSense Project in August 2017 (Loftis et al., 2017a).

Water level observations have been made in the region since the installation of the Sewells Point Gauge by NOAA in 1927 on Naval Station Norfolk. The long-term measurements, such as those at Sewells Point, are critical for determining the long-term relative sea level rise rates and potential changes in rates, that is, the acceleration of sea level rise seen in the region (Boon, 2012; Ezer \& Corlett, 2012). Since the initial installation, many more have been installed to improve flood forecasting, navigation, and delineation of the regional variability in sea level rise rates. As technology has advanced and associated hardware costs have become more affordable, a higher-density network of sensors is more tenable and affordable for the Hampton Roads community. The proliferation of Internet of Things (IoT) sensors and communications technologies has made these water level measuring technologies more affordable to local and regional entities in Hampton Roads. This development in sensor availability is critical, as the predictive capabilities of flood forecasting through hydrodynamic models (like those being developed at VIMS) 
have begun extending into the urban street-scale and could benefit from denser validation data sets. Ultimately, validations in more places throughout a city are needed to ensure a model's efficacy and aid improvement.

In 2008, NOAA published a gaps analysis in a technical memorandum reviewing relative coverage of regions with their sensors and originally identified few locations with need for data coverage in Chesapeake Bay and its tributaries (Gill \& Fisher, 2008). No gaps were noted in Hampton Roads in Figure 11 of their report. However, NOAA's directive has a national viewpoint, and projected sea level rise trends and decreased costs for monitoring technology have enabled the region to respond more proactively to more frequent flooding. Due to the dendritic shape of the many estuaries of Hampton Roads, changes in prevailing wind directions combined with estuarine circulation contribute to flooding in ways that cannot be best understood by a single sensor at each major river mouth.

In a recent presentation to the Hampton Roads Planning District Commission's Regional Resilience Working Group, a more regionally resolute simulated gaps analysis review of 85 new suitable bridgemounted water level sensor locations throughout Hampton Roads was presented (Loftis et al., 2017b). Suitability was determined by Lidar-detected deck heights for all bridges over open tidally connected waterways. The sites were identified by using hydrodynamic modeling simulations compared with the existing sparse network of sensor observations, and then a list was exported favoring sites that were $<85 \%$ match in predictions, when compared with the next nearest suggested location during heavy wind conditions, and $<95 \%$ match during regular tidal conditions. Of the 85 sites reviewed, 22 new suggested sensor sites were discovered as priority lo-

\section{FIGURE 2}

Analysis map of 85 bridges in the Hampton Roads region with sufficient deck height for installation of new water level sensors (in gray). Twenty-two sites were identified as priority sites (in red), where new sensors would be of research value. Existing NOAA and USGS water level monitoring stations are shown in blue and green, respectively, and were also considered in this analysis. Click Figure or http://arcg.is/1TW049 for dynamic map.

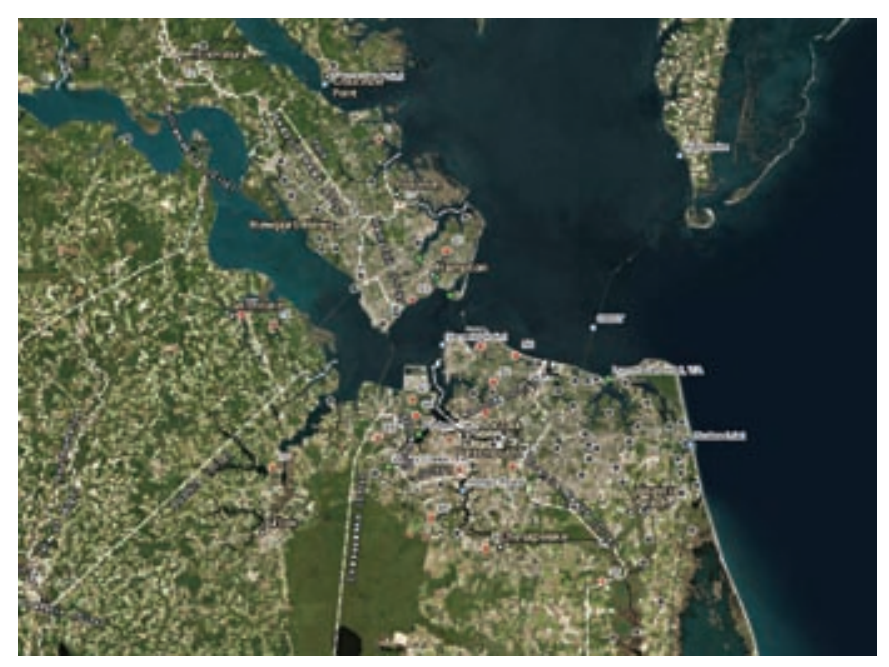

cations with bridges of sufficient elevation with consideration of projected sea level trends (Loftis et al., 2017b). A map of those suggested sites are presented in Figure 2, and a small number of these sites have since had sensors installed nearby by StormSense or the USGS. StormSense's data portal is accessible at http://aws. vbgov.com/stormsense, and the project's water level data are viewable at http://www.stormsense.com.

\section{NOAA CO-OPS}

The NOS Center for Operational Oceanographic Products and Services (CO-OPS) has two NOS programs that support observations in the region: The National Water Level Observation Network (NWLON) and the Physical Oceanographic RealTime System $\left(\right.$ PORTS $^{\circledR}$ ).

Long-term water level measurements are made at the NWLON stations. They are critical components for observing sea level rise in the region. There are 10 NWLON stations in Virginia and six in Hampton Roads (shown in blue in Figure 2). These stations are, in order of priority by length of data record, (1) Sewells Point, (2) Chesapeake Bay Bridge Tunnel (CBBT), (3) Money Point, (4) Yorktown U.S. Coast Guard Training Center, (5) Cape Henry, VA, and (6) CBBT Chesapeake Channel: https://tidesandcurrents.noaa.gov/ stations.html?type $=$ Water + Levels\# Virginia. It should be noted that the gauge at (2) above has been moved nearly 6 miles northeast to the Chesapeake Channel of the CBBT (6) due to construction, and some NOAA sites show (5) as having water levels, but these simply show data from (6), thus (5) only has unique meteorological data. 


\section{USGS National Water \\ Information System}

The USGS National Water Information System has 28 water level stations in Virginia, 19 of which are located in the Hampton Roads region (shown in green in Figure 2; including one recurring temporary monitoring site in Norfolk's Hague). All of the USGS Hampton Roads assets were established in the last 2 years through cooperative agreements with localities through Hurricane Sandy Relief funds that had to be appropriated and spent by the end of 2016 . Thus, the Richmond Field Office has no immediate plans for further development. In 2015, four sensors were installed in Hampton, three in Chesapeake, one in Portsmouth, one in Suffolk, one in Gloucester, and one in Virginia Beach, with eight more sensors installed in Virginia Beach in 2016: https://waterdata. usgs.gov/va/nwis/current/?type=tide $\&$ group_key=basin_cd

\section{Tidewatch}

VIMS operates and maintains a water level monitoring and prediction service called Tidewatch, which now operates under the CCRFR. Many of the individuals involved in the IPP SAC are now involved in advising, operating, and modeling at this new state-funded flood center. In its present state, Tidewatch mostly ingests Web service data streams for NOAA-monitored water levels in Chesapeake Bay for eight of its locations. However, Tidewatch will be used as a starting point to integrate sensors throughout the region to create a resilience monitoring network. Within its present installation of 10 sites, two monitoring locations are unique to the network owned and operated by the CCRFR. One is a new
2017 installation outside of Hampton Roads at Tangier Island, VA, whereas the other is within Hampton Roads in Back River's Dandy Haven, available at http://www.vims.edu/bayinfo/ tidewatch/stations/brdh/index.php.

\section{WeatherFlow, Inc.}

WeatherFlow is a company that collects extensive wind and selected water level observations. WeatherFlow installed its first microwave water level sensor on the Wythe Creek Bridge in Poquoson, VA. This sensor fills a gap in the area between NWLON sites at Yorktown and Sewells Point and can be seen on the WeatherFlow DataScope Web portal (http://datascope. weatherflow.com/). Their data are accessible on a subscription basis. WeatherFlow also provides forecasts, nowcasts, and continuous wind data to subscribers via sector-specific portals (e.g., iWindsurf.com, iKitesurf. com, FishWeather.com, and SailFlow. com).

\section{StormSense}

StormSense is an IoT-enabled inundation forecasting research initiative and an active participant in the Global City Teams Challenge seeking to enhance flood preparedness in the smart cities of Hampton Roads, VA, for flooding resulting from storm surge, rain, and tides (Loftis et al., 2017a). In this study, we present the results of the new StormSense water level sensors to help establish the "regional resilience monitoring network" noted as a key recommendation from the IPP. To accomplish this, the Commonwealth Center for Recurrent Flooding Resiliency's Tidewatch tidal forecast system is being used as a starting point to integrate the extant (NOAA) and new (USGS and StormSense) water level sensors throughout the region and demonstrate replicability of the solution across the cities of Newport News, Norfolk, and Virginia Beach within Hampton Roads, VA (Loftis et al., 2018). StormSense's network employs a mix of ultrasonic and radar remote sensing Io $\mathrm{T}$ technologies to record water levels in 6-min intervals at 28 locations around Hampton Roads established in 2017. More details on data and locations of sensors are listed on the project's website, http://www.stormsense.com.

\section{Subsidence Observations}

Approximately one half of the relative sea level rise in Hampton Roads is caused by land sinking (Eggleston \& Pope, 2013). Thus, it is imperative that the rates and spatial variability of subsidence be well known. Subsidence is measured using GPS, Synthetic Aperture Radar satellites, and extensometer techniques. The most comprehensive subsidence measurements for the area cover the time period from 1940 to 1971, depicting subsidence across the region that is relatively constant spatially at a level of approximately $2-3 \mathrm{~mm} /$ year. This subsidence is assumed to be due to the presence of large-scale subsidence signals associated with the glacial isostatic adjustment, groundwater withdrawal, and ongoing shifts associated with the Chesapeake Bay meteor impact crater. Until recently, this assumption was made, in part, because of the lack of higher-resolution information on vertical land motion for Hampton Roads. However, new methods employing a combination of the technologies in the ensuing subsections have enabled us to gain some slight insight into subsidence in Hampton Roads (Bekaert et al., 2017). This section provides details 
on the technologies, programs, and methods used to obtain and access subsidence data.

\section{GPS CORS}

The NOAA National Geodetic Survey manages a network for Continuously Operating Reference Stations (CORS). The CORS provide Global Navigation Satellite System data through the United States, including Hampton Roads. There are a total of six CORS in the Hampton Roads region, although generally located around the fringes with no current coverage in Norfolk, Hampton, or Newport News. The longest record provided by these stations extends back only to 2006, with most CORS having records spanning less than a decade in length.

\section{InSAR}

Using interferometric synthetic aperture radar (InSAR) analysis, it is possible to generate higher spatial resolution (20-30 m) estimates of subsidence in coastal areas (Jones et al., 2016). Several SAR satellites have collected imagery over Hampton Roads in the past decade, although few with enough acquisitions and a long enough record to provide the level of uncertainty needed to obtain useful results from InSAR analysis. The ALOS-1 SAR satellite collected data from 2007 to 2011 over Hampton Roads. In total, 12 acquisitions were obtained over this time period, although several of these acquisitions were made during 2010 and 2011. The ALOS-1 data are freely available from the Alaska Satellite Facility. The data have been processed and used in a recently published study to provide a first look at InSAR-estimated subsidence for the region (Bekaert et al., 2017). Compared to the previous sur- vey from USGS from 1940 to 1971, significant spatial variability was seen in the estimates of vertical land motion for the region, although coupled with relatively large uncertainty as a result of the poor GPS coverage and limited data set that was used. COSMO-SkyMed has provided SAR coverage of Hampton Roads since approximately 2011, although these data are not freely available and subsidence estimates using these data have not been published to date.

For ongoing and future monitoring of Hampton Roads using InSAR, there are other data possibilities. Since 2015, the Sentinel-1 satellite has been acquiring data over Hampton Roads. Starting in September 2016, the satellite began acquiring data over the region every 12 days. Sentinel-1 also samples in the C-band, leading to dramatic reductions in uncertainty introduced by ionospheric noise when compared to the L-band measurements of ALOS-1. Importantly, the European Union Commission has committed to continuing and adding to the Sentinel Constellation until at least 2030, ensuring the ability to monitor subsidence over Hampton Roads. This will eventually lead to dramatic reductions in uncertainties as the time series continues to increase.

\section{Extensometers}

The Hampton Roads Sanitation District (HRSD) will, as part of its Sustainable Water Initiative for Tomorrow (SWIFT) project, install several extensometers. These devices measure surface motion relative to bedrock using a cable which extends through a steel pipe beneath the Potomac aquifer. The data will be available from HRSD or USGS. HRSD's site at www.swiftva.com includes further details regarding the SWIFT initiative.

\section{Topography and Bathymetry}

The inherent need for accurate and resolute topography and bathymetry to build efficient models for prediction and estimation of flood impacts are self-evident. Models are only of value if their input data enable them to address the concern adeptly, and elevation data are the most integral input of both nonconservative topographybased bathtub models and hydrodynamic models. If the shape, elevation of an inundated landform, and any impediments to fluid flow are not correctly accounted for in a model, the results will fail to accurately represent reality (Loftis et al., 2016). The provision of these data products involved implementation of a combination of remote sensing technologies to retrieve-mostly Lidar for topography and Sonar for bathymetry.

\section{NOAA NCEI}

The National Center for Environmental Information (NCEI), formerly the National Geophysical Data Center (NGDC), provides a wide variety of Bathymetry Surveys and Topography data. Bathymetry offerings in Hampton Roads range from raw point returns in the form of (1) multibeam sonar, (2) single-beam (trackline) sonar surveys, to (3) NOS hydrographic surveys or gridded points in the form of (4) bathymetric attributed grids (BAGs) (Figure 3).

1. Multibeam surveys provide six valuable data sets available in Hampton Roads and mostly cover the Norfolk Shipping Channel as depicted in Figure 3A. Surveys occurred on the following dates, listed in reverse chronological order: (1) MGL1409 


\section{FIGURE 3}

Spatial coverage of NOAA-surveyed bathymetry data via $(A)$ six multibeam sonar surveys, (B) four single-beam sonar surveys, (C) 311 NOS hydrographic surveys, and (D) 234 BAGs in Hampton Roads, VA. Of these data, only one multibeam sonar survey was newer than 2010, whereas <30 digitized hydrographic surveys and <30 BAGs were newer than 2010 . URL: https://www.ngdc.noaa.gov/maps/bathymetry/.

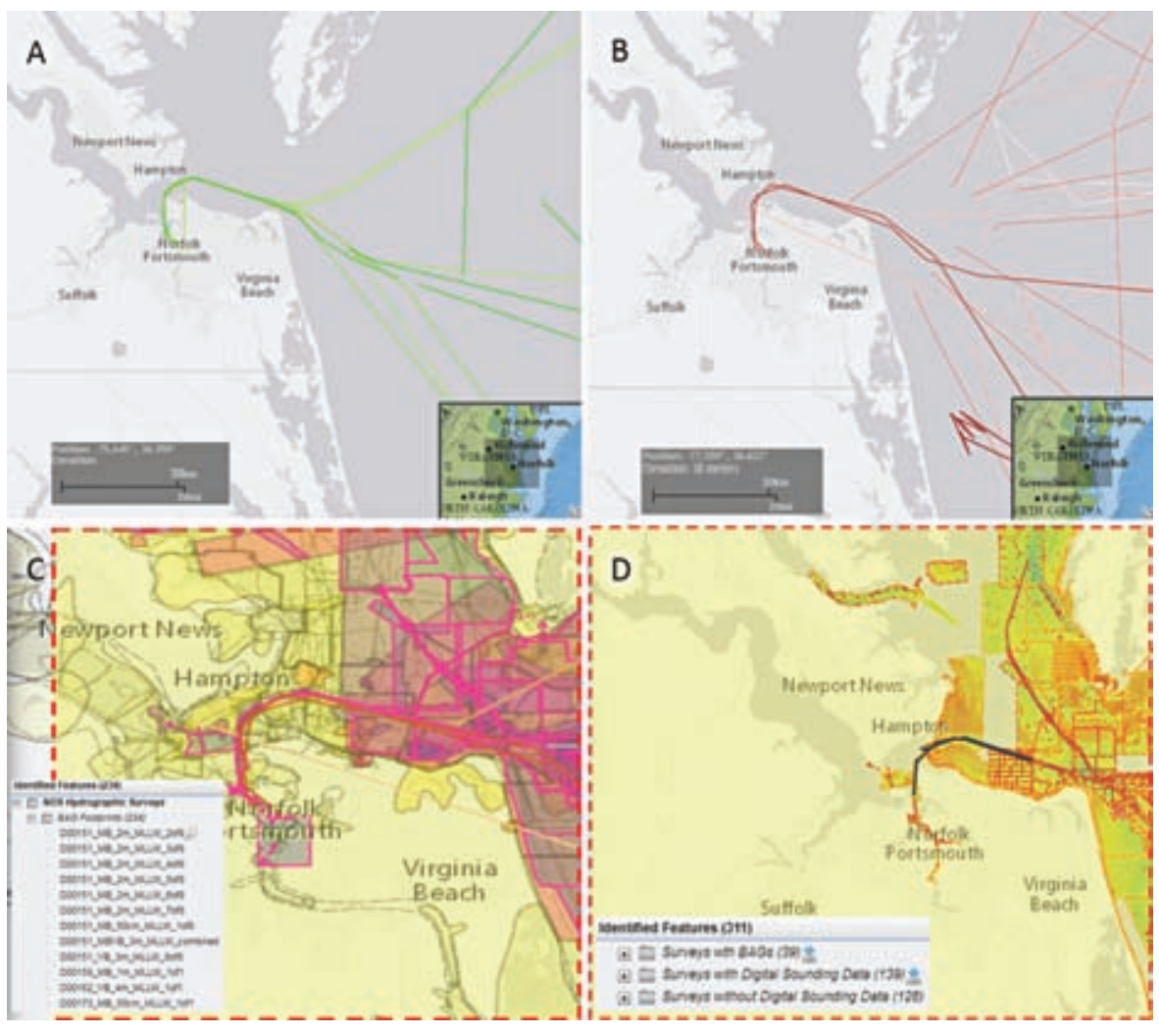

(2014), (2) EW0008 (2000), (3) EW9901 (1999), (4) EW9808 (1998) (after dredging Norfolk Channel), (5) EW9804 (1998) (before dredging Norfolk Channel), and (6) EW9803 (1998) (before dredging Norfolk Channel).

2. Single-beam (trackline) sonar surveys comprise four useful data sets in Hampton Roads and, like the multibeam products, mostly cover the Norfolk Shipping Channel, shown in Figure 3B. The surveys were conducted, as noted in reverse chronological order: (1) EW9901 (1999), (2) EW9803 (1998), (3) LY73A (1973), and (4) OPR425D (1968).
3. Hydrographic surveys account for 311 data offerings, collected and archived by the NOAA NOS. These surveys are truly critical data sets, as they cover all of the navigable waterways of Hampton Roads. In many shallower tributaries to the Chesapeake Bay, these surveys are the only bathymetry data that exist in these systems. In many cases, the surveys are several decades old, and the point spacing or resolution is low: $20-30 \mathrm{~m}$ at best. The data from these hydrographic surveys are often included in derivative merged topobathymetric Digital Elevation Model (DEM) products noted in the next section.
4. BAG data surveys account for 234 variable extent surveys within the Hampton Roads region along the coasts of Virginia Beach, Norfolk, and Hampton, and parts of York and Gloucester Counties. BAG surveys also cover deeper channels of the James and Elizabeth Rivers in Hampton Roads.

NOAA's NCEI also provides combined topobathymetric merged data sets ranging from (in increasing resolution) Global ETOPO5 (5 min), ETOPO2v2 (2 min), ETOPO1 (1 min), satellite measured topography, alongside the global land $1-\mathrm{km}$ base elevation product (30 arcsecond), to the Southeast Atlantic region of the Coastal Relief Model (3 arc-second), down to the Hampton Roads Region's Virginia Beach DEM (1/3 arc-second): https://www.ngdc. noaa.gov/maps/bathymetry/, https:// ngdc.noaa.gov/mgg/bathymetry/ relief.html.

\section{NOAA Digital Coast}

This resource has a plethora of coastal and topobathymetric Lidar data with significant point spacing between returns. The data are available as LAS cloud and GeoTIFF rasters: https://coast.noaa.gov/digitalcoast/ data/. Digital Coast has additional data sets that may be relevant for modeling efforts, including land cover data sets of variable resolution that are of value in establishing spatially varying friction and soil permeability parameterization for hydrodynamic models. NOAA also has two tsunami inundation model gridded Digital Elevation Models (DEMs) for Virginia. There are three nested Virginia Forecast Model grids, which provide bathy-metric data strictly for tsunami inundation modeling with the Method of 
Splitting Tsunami model (https:// data.noaa.gov/dataset/virginia-beachtsunami-forecast-grids-for-mostmodel) and the Virginia Beach $10 \mathrm{~m}$ topobathymetric DEM, also available from the NOAA NGDC portal (Taylor et al., 2008; https://www. ngdc.noaa.gov/dem/squareCellGrid/ download/423).

\section{USGS NED}

The USGS National Elevation Dataset (NED) has been a mainstay for surface topography data in the region for a long time. Their product offerings include variable formats of DEMs ranging from $1 \mathrm{~min}$ to $1 / 9$ arc-second in resolution throughout Hampton Roads. Their more recent $1 / 3$ and $1 / 9$ arc-second DEMs offer some limited hydrocorrection for large culverts and large ditches (Evans, 2010; https://lta.cr.usgs.gov/NED). In addition, the USGS has developed a 1-m resolution merged DEM composed of the "best available data" (Evans, 2010) from the above-listed topography and bathymetry data sources for the entire Chesapeake Bay watershed, including all of Hampton Roads (Danielson et al., 2016; Thatcher et al., 2016).

\section{VITA VGIN}

The Virginia Information Technologies Agency's (VITA) Virginia Geographic Information Network (VGIN) provides elevation data throughout parts of the Commonwealth where available. Currently, their digital topography holdings cover all of coastal Virginia, including Hampton Roads. These elevations were obtained through Lidar surveys over an 8-year acquisition period and are downloadable as LAS point cloud data and bare earth Lidar DEMs (Scrivani, 2016). Lidar
DEMs are available through VGIN's data portal and through ArcGIS Online feature services, and like the USGS NED layers, these Lidar holdings have limited hydrocorrection. VGIN also includes other flood riskrelated shape files including Building Footprints and Parcel layers, where available. VITA's goals in providing services through VGIN will be extended to include Lidar throughout the rest of Virginia by 2020 according to their current 2015-2020 plan (VGIN VITA, 2015).

\section{Wave Measurements}

Observations of ocean waves in the region are important to predict overtopping of and impact loads on coastal structures, quantify shoreline erosion, and understand the storm risk to residential buildings in the coastal zone and to maritime safety. Since waves, either wind waves or boat wakes, are high-frequency water surface motions, wave measurements are carried out by sensors that can measure water level at high temporal resolution. The subsequent sections outline wave measurements from
Scripps, NOAA, and sporadic alternative sources.

\section{CDIP}

The Coastal Data Information Program (CDIP) at the Scripps Institute of Oceanography, University of California, San Diego, leads an extensive nationwide network for monitoring waves. In collaboration with regional partners, CDIP operates five Datawell Directional Waverider Buoys in the expanded region. Two buoys are located near the mouth of the Chesapeake Bay. To the north, a buoy is deployed off Wallops Island, and to the south, two more are deployed off Duck, NC. The wave buoy data are provided on the CDIP web page at http://cdip. ucsd.edu and to the National Buoy Data Center (NDBC) and CO-OPS for further dissemination. These Datawell buoys are exclusively designed to observe waves with high accuracy and are often used for model validation (Hanson et al., 2014) (Figure 4).

\section{NOAA's CBIBS}

Additional wave measurements are provided by buoys within the Chesapeake Bay (Figure 5) as part

\section{FIGURE 4}

(A) The CDIP at Scripps is funded by the U.S. Army Corps of Engineers to maintain an array of Datawell wave buoys. (B) Datawell wave buoys are designed specifically to provide high-quality wave observations. The wave buoy data are provided on the CDIP Web page at http://cdip.ucsd. edu and to NDBC and CO-OPS for further dissemination.
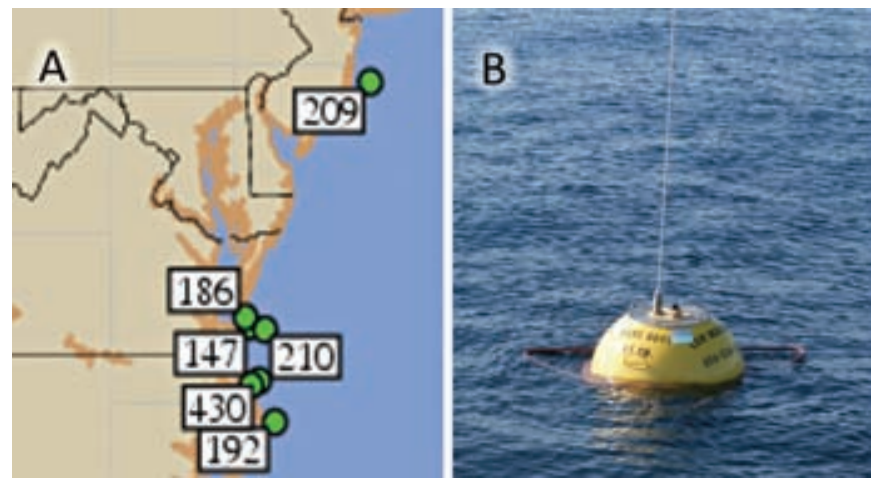


\section{FIGURE 5}

(A) NOAA's CBIBS maintains an array of buoys within the Bay. (B) CBIBS buoys support a variety of sensors, providing wave, current, water quality, and meteorological observations. Data are available at: https://buoybay.noaa.gov.
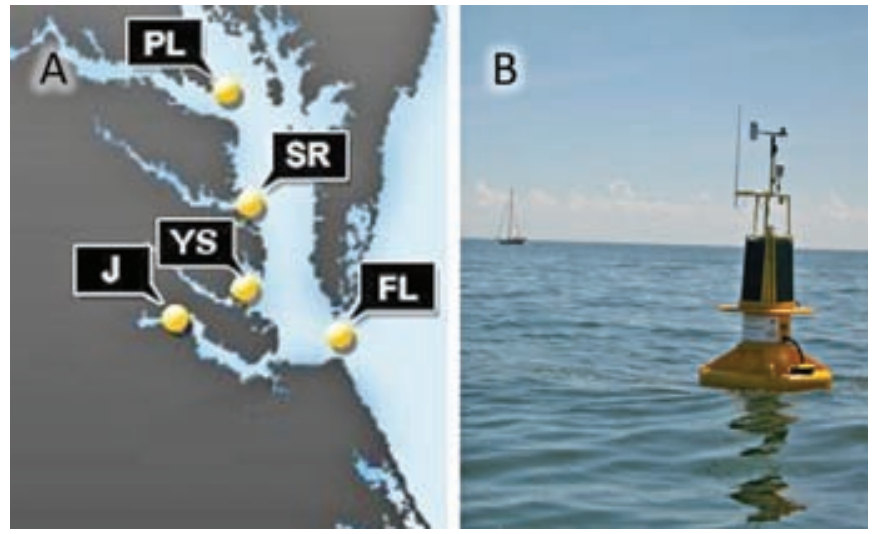

of NOAA's Chesapeake Bay Interpretive Buoy System (CBIBS; https:// buoybay.noaa.gov). The wave observations are obtained from buoys that have a superstructure supporting meteorological observations. Within the vicinity of Hampton Roads, CBIBS buoys are located at First Landing, Jamestown, York Spit, and Stingray Point. The data are made available for viewing and download on their website.

\section{Other Wave Measurements (Bottom- Mounted Sensors and ADCPs)}

Although wave buoys are suitable to measure waves in deep waters, wave measurements in shallow waters (less than $\sim 10$ m depths) are commonly carried out using bottom-mounted instruments. Bottom-mounted sensors include pressure gauges that measure water level at high temporal resolution and acoustic sensors such as acoustic Doppler current profilers (ADCPs) that can measure waves in addition to currents. Single-pressure gauges can only obtain nondirectional wave measurements, whereas multiple-pressure gauges or an acoustic Doppler current profiler can obtain directional wave breakwaters and oyster reefs. The data sets, a map of the sites, and information on layout of the gauges can be found at www.odu.edu/coastal/living shorelines. The value of these data increase as sea levels are projected to rise and wetlands in the intertidal zone begin to drown and retreat landward. In the context of resilience, the measured wave intensity at sensors can help support longevity of investment claims with regard to seeding potential and root strength of vegetation for living shorelines over gray infrastructure alternatives in the face of current and future storms.

\section{Current Measurements}

Ocean current measurements are made to support real-time models, search and rescue, and engineering projects. Currents are measured directly by ADCPs attached to buoys or, indirectly, by high-frequency radar. These models could be interpolated products using streamflow and ADCP measurements near river mouths to estimate velocities at various stream segments using mathematical tree models and Geographic Information System (GIS). Hydrodynamic models could also use these data to verify cross-sectional transport estimates near sensors, calculate residence time, or verify flow intensity during aperiodic storm events. The following sections review resources for ADCPs and highfrequency radar gauges measuring currents in Hampton Roads.

\section{ADCP Current Measurements}

NOAA's PORTS program operates current meters attached to aidsto-navigation buoys at three locations in the lower Chesapeake Bay. These Doppler profilers provide data in the Thimble Shoals and Chesapeake shipping channels. A description of the 
operation of these instruments is found in NOAA Technical Report NOS CO-OPS 043 titled "Test, Evaluation, and Implementation of Current Measurement Systems on Aids-toNavigation" (Bosley et al., 2005). Three more current meters provide velocity data in the lower James River. One of those, located at Dominion Terminal, has a horizontal orientation in order to measure currents in bins referenced to distance from the pier. These PORTS currents data are collected on a 6-min time interval, and data may be accessed through https:// tidesandcurrents.noaa.gov/ports/index. html?port=cs. The current observation record in the lower Bay is further enhanced by a current profiler attached to the First Landing (FL) CBIBS buoy near Cape Henry $\left(36.9981^{\circ} \mathrm{N}\right.$, $\left.-76.0873^{\circ} \mathrm{W}\right)$. Data from this buoy are available at https://buoybay.noaa. gov/locations/first-landing\#quicktabslocation_tabs $=0$.

\section{High-Frequency Radar Surface Current Measurements}

The Center for Coastal Physical Oceanography (CCPO) at Old Dominion University (ODU) maintains six high-frequency radar stations with funding from NOAA's Integrated Ocean Observing System office and the Mid-Atlantic Regional Association Coastal Ocean Observing System (MARACOOS). Three highresolution radar systems operating at $25 \mathrm{MHz}$ measure surface currents in the lower Chesapeake Bay. Station data are combined to produce hourly maps of current vectors on a grid with $2-\mathrm{km}$ spacing. Data coverage extends from the Bay mouth to the mouth of the James River and north of Kiptopeke, VA. The antennas are located at Ocean View Community Beach in Norfolk, Joint Expeditionary Base
Little Creek-Fort Story in Virginia Beach, and Sunset Beach Resort in Cape Charles. There are also three long-range radar systems operating at $5 \mathrm{MHz}$, which are located on Atlantic Ocean beaches. They measure coastal ocean currents out to a maximum range of $200-250 \mathrm{~km}$ offshore. The long-range data are combined to create hourly maps of current vectors on a $6-\mathrm{km}$ spaced grid. The antennas are installed at Little Island Park in Virginia Beach, VA, on the north end of Cedar Island off of Wachapreague, VA, and at the Assateague Island National Seashore, MD.

The ODU radar stations contribute to a regional, national, and global high-frequency radar network, and data are output in near real-time for public use. The data are freely available for visualization and download (THREDDS servers) on the National HFRadar Network website http:// cordc.ucsd.edu/projects/mapping/), hosted by the Coastal Observing Research and Development Center at University of California, San Diego. The data are also available on the Global HF Radar Network (http:// global-hfradar.org/). The 6-km gridded data product is automatically sent to an Environmental Data Server for use in the U.S. Coast Guard search and rescue planning tool. NOAA generates tidal current predictions using lower Chesapeake Bay radar currents and displays those forecasts on its CO-OPS website (https:// tidesandcurrents.noaa.gov/hfradar/ Hfscm.jsp?port=CHES). For more information on local and regional products, visit the CCPO HF radar project website (http://www.ccpo. odu.edu/currentmapping) and the MARACOOS HF radar website (https://maracoos.org/node/146).

\section{Weather Observations}

Observations of weather parameters, such as air temperature, barometric pressure, wind speed, and relative humidity, are routinely made by the National Weather Service with regional organizations and companies providing additional data. There is a relative paucity of observations over water, which could impede more accurate forecasting and understanding of future impacts. The following sections outline resources provided by the National Weather Service, NOAA, and WeatherFlow.

\section{National Weather Service}

The regional Weather Forecast Office (WFO) nearest to Hampton Roads is located in Wakefield, Virginia. This WFO covers southeastern Virginia, northeast North Carolina, and the eastern shore of Virginia (http://www. weather.gov/akq/). They maintain surface weather observations in the region and the Nexrad radar system. Land and ocean observations, forecasts, and climatology data are listed at their website.

\section{NOAA PORTS}

The PORTS observing system in Hampton Roads makes a variety of wind, current, temperature, salinity, and atmospheric observations to serve the maritime community (https:// tidesandcurrents.noaa.gov/ports/index. html? port $=\mathrm{cs})$. NOAA produces, through their PORTS program, Automated Real-Time Narrative Summaries (ARNS) for each station, which may prove useful for audible summary data for each station or a group of stations via voice-activated querying, which is becoming increasingly popular via Amazon Alexa, Google, Apple's Siri, and Microsoft's Cortana. Limited documentation on 
ARNS is here: https://tidesandcurrents. noaa.gov/arns.html.

noaa.gov/phod/floridacurrent/index. php.

\section{WeatherFlow, Inc.}

WeatherFlow, Inc., recently instrumented the Chesapeake Light Tower, located 14 miles off the shore of Virginia Beach after the site was abandoned by NOAA. The site now includes atmospheric and water level observations. WeatherFlow colocated sensors as part of the Virginia Offshore Wind Energy Development. Data are currently privately available for this and other sites on the WeatherFlow DataScope site (http://datascope.weatherflow.com/). WeatherFlow, Inc., operates approximately 20 proprietary weather stations in the Hampton Roads area. Data from those stations are available through several WeatherFlow apps, with some of the data being visible to free users of those apps and the remainder of the data being visible only to users who pay a subscription fee to get an upgraded version of those WeatherFlow apps.

\section{Gulf Stream Dynamics}

On long-term time scales, weakening of the Gulf Stream has been linked with acceleration in sea level rise along the U.S. East Coast, especially north of Cape Hatteras (Boon, 2012; Ezer, 2015; Ezer et al., 2013; Sallenger et al., 2012). On short time scales of days to weeks, variations in the Gulf Stream transport that can be detected by the daily cable measurements of the Florida Current are linked with unpredictable anomalous water level elevation that can cause "clear day" tidal flooding (Ezer \& Atkinson, 2017; Ezer et al., 2017). Gulf Stream transport is measured daily across the Straits of Florida and reported at http://www.aoml.

\section{Data Integration \\ Services (Web-Based \\ Data Consolidators)}

For resiliency planning, a critical component of integrated data collection is the dissemination of the data in a digestible format for decision makers. The variety of data that is available in the region combined with a variety of user needs has led to a variety of websites that integrate various parts of the overall observing system. Many of the data integrating sites have a nationwide scope, whereas others are specific to the region. All provide a valuable service. Some examples of data integration sites that are ingesting data from the Hampton Roads observation network are described below.

\section{Integrated Data Portals and Viewers}

These provide the ability to access different types of data through a single server. Portals are typically aimed at users who want to do their own analyses and provide information to unsynthesized data. Viewers provide mapped and synthesized data tools for resilience planning. The geographic scope of the data portals and viewers varies from national to local, and some examples of prominent portals and viewers are noted below (although a more exhaustive list is provided in Appendix B):

- NOAA's Sea Level Rise viewer allows the user to visualize potential impacts from sea level rise through interactive maps and photos in landmark locations that have been digitally altered to create an oblique view of flooding at thresh- olds up to 6 feet above MSL: https://coast.noaa.gov/digitalcoast/ tools/slr.

- Climate Central's Surging Seas viewer (http://www.ClimateCentral.org) covers most of the U.S. coastal states and allows integrated mapping of social, economic, and flood risk factors. It allows easy comparison of different scenarios to facilitate decision-making up to -32 feet above MSL.

- AdaptVA (http://www.AdaptVA. org) is a site dedicated to providing climate-related data specifically curated for adaptation efforts in Virginia. It provides both a data portal (a geoportal) and synthesized information, targeting different users with each. The geoportal is primarily built to deliver Virginia specific data but will also search ArcGIS.com for global data. All of the synthesized data tools are specific to Virginia.

- Part of the U.S. Integrated Ocean Observing System, the MARACOOS (http://www.MARACOOS.org) serves as a portal for data from the coastal region extending from Cape Cod, MA, to Cape Hatteras, NC. MARACOOS integrates, analyzes, and applies information to best serve their diverse stakeholder communities and to meet enduser needs. They provide marine, atmospheric, and hydrodynamic data from multiples sources and list their priorities for data inclusion as follows: maritime safety, ecological decision support, water quality, coastal inundation, and energy. Much of the observational data, satellite data, and forecast models are available for viewing, download, and analysis through their OceansMap Viewer and tool: http://oceansmap.maracoos.org/. 


\section{Forecast Services}

These provide water level forecasts based on integrated water and atmospheric observations. NOAA National Weather Service and the Virginia Institute of Marine Science's Tidewatch both have water level forecasting systems (http://water.weather.gov/ahps/ and http://www.floodingresiliency. org/water-level-predictions/, respectively) for the Chesapeake Bay region. Although the algorithms are slightly different, they both use wind forecasts and water level observations to graph forecasted water levels at tide gauges and water sensors. Both provide an effective way to measure, visualize, and predict the magnitude and impacts of coastal flooding at locations within the Chesapeake Bay and along Virginia's seaside Eastern Shore. These systems can be used to prepare for storm tides and minimize potential flood impacts. On a longer temporal scale, sea level forecasts are also provided by VIMS (http://www. vims.edu/slrc) for a number of stations. These forecasts are based on relative sea level rise trends at tide gauges throughout the United States and are updated semiannually.

\section{Public Web Service URLs}

Web services from water level sensors and other flood-relevant monitoring assets are often ingested by the viewers and forecast services previously noted in this section. The main three water level monitoring groups with publicly accessible Web services in Hampton Roads are NOAA, USGS, and StormSense.

- NOAA's Tides and Currents site provides a sizable number of integrative services through a variety of interoperable data formats including XML, JSON, and CSV formats for the six sensors in/around
Hampton Roads. These stations (in order of length of data record) are noted in the dynamic digital Appendix A (http://www. vims.edu/people/loftis_jd/ HRVASensorAssets/index.php) in the following order: (1) datum, (2) water levels, (3) tide predictions, (4) air temperature, (5) barometric pressure, and (6a) wind speed with (6b) direction, (7) conductivity, and (8) water temperature (https:// tidesandcurrents.noaa.gov/api/).

- USGS employs public Application Programming Interfaces (APIs) to share the data services they provide. Aggregation links for water levels (and additional parameters, if the city co-opted for other sensors) in Virginia Beach, Hampton, Gloucester, and Chesapeake are available for the 27 sensors the USGS maintains in the region. Other stations can also be retrieved this way if their station names are known and queried within the URLs noted in Appendix A.

- StormSense in Hampton Roads includes the 28 new water level sensors noted in the Water Level Observations section, which are currently publicly broadcasting their water levels under the public API URLs presented in Appen$\operatorname{dix}$ A. StormSense also provides the tools to accept data streams from various other sources with disparate data formats, as recently displayed before and during Hampton Roads' 2017 king tide forecast and sizable coordinated monitoring event, "Catch the King” (Loftis et al., 2017c): http://www.vims.edu/people/ loftis_jd/Catch $\% 20$ the $\% 20$ King $\% 20$ Forecast $\% 20$ Nov\%205th/ index.php. In this instance, Tidewatch was used as a starting point to integrate StormSense and NOAA sensors throughout the region in pursuit of creating a resilience monitoring network to directly address a key recommendation from the IPP.

\section{Summary and Recommendations}

The IPP Science Advisory Committee had a number of recommendations in the final report. The third recommendation was directly relevant for sensor observations and stated that "...the SAC provide a mechanism to assure that the sea level rise science needs and requirements of regional stakeholders are addressed" (Steinhilber et al., 2016; Toll, 2018). They further advised that this could be accomplished through coordination between all levels of government and relevant private organizations for data collection and the delivery of data through integrated Web portals. These goals have been accomplished; however, there were a number of challenges that needed to be overcome. Both establishment of data standards and funding of network sensors have been major concerns. It should be noted that federal funding to NOAA, USGS, and NASA who maintain the land, ocean, and remote sensing instruments is crucial, yet it is expected that network funding may continue to be a concern.

\section{Challenges for Establishing an Integrated Network of Measurement Assets \\ Data Communications Standards}

Most of the cities in the region are installing their own water level gauges employing a broad range of sensor types ranging from (1) $\mathrm{K}_{\mathrm{a}}$-band 
radar, as used by NOAA and USGS, to the cheaper (2) ultrasonic sonar, as remote sensing observation methods, to (3) in situ pressure transducers, which tend to biofoul in the fall tidal floods when harmful algal blooms are more frequent. With industrial IoT technologies, cost savings are realized in communities by eschewing the more costly Iridium Satellite uplink communication methods NOAA and USGS use in favor of $4 \mathrm{G}$ cellular broadband signals, $2 \mathrm{G}$ machineto-machine through Ingenu, and long range wireless area networks. These IoT communication methods, combined with cheaper ultrasonic sensors, result in a reasonably accurate $(-10 \mathrm{~cm})$ affordable water level monitoring alternative for modern smart cities at a cost of $\sim 10 \times$ cheaper, per sensor (Loftis et al., 2017a).

The reality is that, although cities may have ample Public Works and Data Scientists capable of installing and managing their own data, the data types, collection intervals, formats, and error metrics should be standardized. Thus, this approach is still likely to be out of the realm of affordability in rural localities for at least the next decade. It should also be noted that IoT approaches, though cheaper, are potentially more susceptible to interrupted communications during heavy flood events coincident with power outages. Although IoT water level sensors are powered by large solar panels and batteries, their communications are still subject to the same overburdened cellular Internet and data channels most denizens rely on when the power and Internet are offline.

\section{Funding and Resource Sustainability}

For the engaged cities installing sensors in Hampton Roads, most are either collaborating via cooperative agreement with the USGS Richmond Field Office or VIMS through the Smart Cities StormSense Project to locate suitable sites, procure and install the sensors, and make the data public. It is important to assure that the observations are of sufficient accuracy and that they are made public in near-real time. To be sure of this, StormSense is funded through a Replicable Smart City Technologies Cooperative Agreement awarded to the City of Newport News and VIMS, who have been directly advised by the National Institute of Standards and Technology. The data streams coming from the StormSense sensors emulate USGS' data standards by collecting data in 6-min time intervals and reporting their water levels relative to NAVD88 while broadcasting their data via public APIs in a variety of digestible data formats. By making all new water level sensors public in near-real time, the observations can be used for forecasting, emergency management, and research projects.

\section{Creating Integrated Data Products}

The frequency at which different types of data are upgraded can significantly impact the integration of multiple data into a single model or data product. For example, bathymetry is rarely updated, whereas the water level sensors are updated on 6-min time scales. This means that storm surge models are working with detailed changes in water level, but the water levels may be superimposed on inaccurate depths, hampering the improvement of the models.

In Hampton Roads, bathymetric surveys outside of the dredged primary shipping channels are relatively outdated and somewhat sparse in terms of point spacing. Given that shallower streams' hydrographic sur- veys are frequently integrated as the only digitized bathymetry source, shallow stream systems, such as the Lynnhaven, Nansemond, Back, and Lafayette Rivers do not have the best possible bathymetry data for adequate consideration of flood risk in Hampton Roads. Refined bathymetry would result in an immediate improvement of flood forecasting.

\section{Recommendations}

In completing this inventory of observations and data formats, a number of key determinations can be formulated into recommendations for filling gaps, leveraging historical continuity of observations, and integrating systems for improving situational awareness in emergencies as well as broadbased information needs for resilience planning. An overall premise is that integration of diverse observing systems into a network is vital for resilience planning, which inherently crosses sectors and space-time scales. First, as each observing network arose out of a particular sector or scientific or geotechnical discipline, it is prudent to inventory and define data standards early when inputs are sought across networks. Interoperability issues comprise technical issues of communications and data formats, standards of unit measurements, and application requirements in temporal and spatial collection needs (extent, resolution, and temporal frequency). We find that shallow-water bathymetry continues to be a constraint on hydrodynamic modeling, and efforts to systematically map and update this parameter will result in better forecasting and planning process inputs. Likewise, topographic data, already greatly enhanced by Lidar DEMs, could be further improved with finer resolution, use of hydrocorrection in disjunct, low-lying areas, and 
leverage research on subsidence for developing future topographic representation (and inundation models) for relative sea level rise (combining eustatic rate scenarios and subsidence trends). In addition, the growing network of real-time water level sensors ought to be expanded to allow forecasting to better predict storm surge impacts as well as wind tides and nuisance flooding. Finally, overall integration of ocean, earth, and atmospheric observations should be sought to enhance situational awareness in emergency events as well as promote scientific analysis and prediction. With these recommendations in mind, these sensor data should be used to help the public, stakeholders, and policy makers in the near term by recognizing when their home or vehicle is in danger of flooding in near-real time and validate predictive model results for future improvement. Simultaneously, this integrated network of sensors will aid in resilience efforts through research into compounding effects of sea level rise and subsidence in Hampton Roads in the long term.

\section{Acknowledgments}

The authors would like to thank the IPP SAC for their thought and guidance in advising Hampton Roads toward a more resilient future and MTS for recognizing the value of those decisions in assembling this special issue. We would like to thank NOAA, USGS, NWS, NASA, StormSense, and WeatherFlow for their publicly shared data observations outlined in this paper and their myriad uses for scientists, decision makers, and stakeholders in the pursuit of sustainable resilience. In addition, thank you to those organizations who have taken these useful data products and aided their interpretation through interactive viewers through NOAA, USGS, MARACOOS, AdaptVA, and Climate Central, among others. Finally, thank you to the reviewers from MTS whose conscientious comments invariably improved this manuscript during the peer-review process. This paper is Contribution No. 3728 of the Virginia Institute of Marine Science, College of William \& Mary. The research was carried out in part at the Jet Propulsion Laboratory, California Institute of Technology, under a contract with the National Aeronautics and Space Administration. A portion of the publication costs for this paper were furnished by NASA's Disasters Program through federal award \#NNL16AA05C/21617- 050 .

\section{Corresponding Author:}

Jon Derek Loftis

Center for Coastal Resources

Management, Virginia Institute

of Marine Science,

College of William \& Mary

1208 Greate Road, Gloucester Point,

VA 23062

Email: jdloftis@vims.edu

\section{References}

Bekaert, D.P.S., Hamlington, B.D., Buzzanga, B., \& Jones, C.E. 2017. Spaceborne synthetic aperture radar survey of subsidence in Hampton Roads, Virginia (USA). Sci Rep. 7:14752. https://doi.org/10.1038/s41598-017-15309-5.

Boon, J.D. 2012. Evidence of sea level acceleration at US and Canadian tide stations, Atlantic Coast, North America. J Coast Res. 28(6):1437-45. https://doi.org/10.2112/ JCOASTRES-D-12-00102.1.

Boon, J.D., \& Mitchell, M. 2015. Nonlinear change in sea level observed at North American tide stations. J Coast Res. 31(6):1295-305. https://doi.org/10.2112/JCOASTRES-D15-00251.1.
Boon, J.D., Mitchell, M., Loftis, J.D., \& Malmquist, D.M. 2018. Anthropocene sea level change: A history of recent trends observed in the U.S. East, Gulf, and West Coast Regions. Special Report in Applied Marine Science and Ocean Engineering (SRAMSOE), No. 467. Virginia Institute of Marine Science, College of William \& Mary. https://doi.org/ 10.21220/V5T17T.

Bosley, K.T., McGrath, C., Dussault, J.P., Bushnell, M., Evans, M.J., French, G.W., \& Earwaker, K.M. 2005. NOAA Technical Report, NOS CO-OPS 043 Ocean Systems Test and Evaluation Program Test, Evaluation, and Implementation of Current Measurement Systems on Aids-ToNavigation Silver Spring, Maryland. Available at: https://tidesandcurrents.noaa.gov/ publications/technical_report_43.pdf. (accessed November 1, 2017).

Boswell, M. K., \& Tahvildari, N. 2017. Investigating wave dissipation effects of living shorelines (Abstract). ASCE-EWRI Congress, Sacramento, CA.

Danielson, J.J., Poppenga, S.K., Brock, J.C., Evans, G.A., Tyler, D.J., Gesch, D.B., ... Barras, J.A. 2016. Topobathymetric elevation model development using a new methodology: Coastal national elevation database. J Coast Res. 76(sp1):75-89. https://doi.org/10.2112/ SI76-008.

Eggleston, J., \& Pope, J. 2013. Land Subsidence and Relative Sea-Level Rise in the Southern Chesapeake Bay Region: U.S. Geological Survey Circular 1392. 30 p. https:// doi.org/10.3133/cir1392.

Evans, G. 2010. National elevation dataset. U.S. Geological Survey Earth Resources Observation and Science (EROS) Center. VITA Webinar Series, May 20, 2010. Available at: https://www.vita.virginia.gov/media/ vitavirginiagov/integrated-services/pdf/USGS_ NED_Overview.pdf.

Ezer, T. 2015. Detecting changes in the transport of the Gulf Stream and the Atlantic overturning circulation from coastal sea level data: The extreme decline in 2009-2010 and estimated variations for 1935-2012. Global 
Planet Change. 129:23-36. https://doi.org/ 10.1016/j.gloplacha.2015.03.002.

Ezer, T., \& Atkinson, L.P. 2014. Accelerated flooding along the US East Coast: On the impact of sea-level rise, tides, storms, the Gulf Stream, and the North Atlantic oscillations. Earth's Future. 2(8):362-82. https://doi.org/ $10.1002 / 2014 \mathrm{EF} 000252$.

Ezer, T., \& Atkinson, L.P. 2017. On the predictability of high water level along the U.S. East Coast: Can the Florida Current measurement be an indicator for flooding caused by remote forcing? Ocean Dyn. 67(6):751-66. https://doi.org/10.1007/s10236-017-1057-0.

Ezer, T., Atkinson, L.P., Corlett, W.B., \& Blanco, J.L. 2013. Gulf Stream's induced sea level rise and variability along the U.S. midAtlantic coast. J Geophys Res. 118(2):685-97. https://doi.org/10.1002/jgrc.20091.

Ezer, T., Atkinson, L.P., \& Tuleya, R. 2017. Observations and operational model simulations reveal the impact of Hurricane Matthew (2016) on the Gulf Stream and coastal sea level. Dyn Atm Oceans. 80:124-38. https:// doi.org/10.1016/j.dynatmoce.2017.10.006.

Ezer, T., \& Corlett, W.B. 2012. Is sea level rise accelerating in the Chesapeake Bay? A demonstration of a novel new approach for analyzing sea level data. Geophys Res Lett. 39(19): L19605. https://doi.org/10.1029/2012GL053435.

Folke, C. 2006. Resilience: The emergence of a perspective for social-ecological systems analyses. Global Environ Change. 16:253-67. http://www.ecologyandsociety.org/vol15/iss4/ art20/. https://doi.org/10.1016/j.gloenvcha. 2006.04.002.

Gill, S.K., \& Fisher, K.M. 2008. A network gaps analysis for the National Water Level Observation Network. NOAA Technical Memorandum NOS CO-OPS 0048. Available at: https://tidesandcurrents.noaa.gov/ publications/Technical_Memorandum_ NOS_COOPS_0048.pdf.

Hanson, J., Blanton, B., Gamiel, K., Bushnell, M., \& Thomas, J. 2014. Wave Observations and Forecast Modeling to Support Development of Virginia Offshore Wind Energy.
Report submitted to the Commonwealth of Virginia Department of Mines, Minerals and Energy for RFP \#14DE01. Topic 2. Available at: http://wind.jmu.edu/offshore/documents/ Waves\%20Observation\%20and\%20Forecast \%20Modeling\%20to\%20Support \%20Development $\% 20$ of $\% 20$ Virginia $\% 20$ Offshore $\% 20$ Wind $\%$ 20Energy,\%20October\%202014.pdf.

Jones, C., An, K., Blom, R., Kent, J., Ivins, E., \& Bekaert, D. 2016. Anthropogenic and geologic influences on subsidence in the vicinity of New Orleans, Louisiana. Journal of Geophysical Research: Solid Earth. 121(5):3867-3887. https://doi.org/10.1002/2015JB012636.

Loftis, J.D. 2017. "Catch the King” tide thank you and review. CCRFR Thank you and Review Community Event at ODU, Dec. 13, 2017. William \& Mary Publish Digital Archive. https://doi.org/10.21220/V5Z14X.

Loftis, J.D., Forrest, D.R., Katragadda, S., Spencer, K., Organski, T., Nguyen, C., \& Rhee, S. 2018. StormSense: A new integrated network of IoT water level sensors in the smart cities of Hampton Roads, VA. Mar Technol Soc J. 52(2):(in this issue). https://wm1693.box.com/s/ j501 eg525rtqnya41n2dfm6a0o4yx7gh.

Loftis, J.D., Forrest, D.R., \& Spencer, K. 2017b. StormSense Project: Forecasting flooding from storm surge, rain $\&$ tide. William \& Mary Publish Digital Archive. https://doi. org/10.21220/V5GM9B.

Loftis, J.D., Wang, H.V., DeYoung, R.J., \& Ball, W.B. 2016. Using Lidar elevation data to develop a topobathymetric digital elevation model for sub-grid inundation modeling at Langley Research Center. J Coastal Res. 76(sp1): 134-48. https://doi.org/10.2112/SI76-012.

Loftis, J.D., Wang, H., Forrest, D., Rhee, S., \& Nguyen, C. 2017a. Emerging flood model validation frameworks for street-level inundation modeling with StormSense. SCOPE'17 Proceedings of the 2nd International Workshop on Science of Smart City Operations and Platforms Engineering, 2(1):13-8. https://doi. org/10.1145/3063386.3063764.

Loftis, J.D., Wang, H.V., \& Forrest, D.R. 2017c. Catch the king tide with StormSense on Nov. 5th: How you can help crowd-source tidal flood event calibrations for Hampton Roads' newest water level sensors. William \& Mary Publish Digital Archive. https://doi. org/10.21220/V5MB1S.

Sallenger, A.H., Jr., Doran, K.S., \& Howd, P.A. 2012. Hotspot of accelerated sea-level rise on the Atlantic coast of North America. Nat Clim Change. 2(12):884-8. https://doi. org/10.1038/nclimate1597

Scrivani, J. 2016. Introduction to LiDAR in Virginia. VITA Webinar Series. Available at: https://www.vita.virginia.gov/media/ vitavirginiagov/integrated-services/pdf/Lidar. pdf (accessed June 15, 2016).

Steinhilber, E.E., Boswell, M., Considine, C., \& Mast, L. 2016. Hampton Roads Sea Level Rise Preparedness and Resilience Intergovernmental Pilot Project. Phase 2 Report: Recommendations, Accomplishments and Lessons. Available at: http://digitalcommons. odu.edu/hripp_reports/2/. (accessed January 13, 2017).

Taylor, L.A., Eakins, B.W., Carignan, K.S., Warnken, R.R., Sazonova, T., Schoolcraft, D.C., \& Sharman, G.F. 2008. Digital Elevation Model of Virginia Beach, Virginia: Procedures, Data Sources and Analysis, NOAA Technical Memorandum NESDIS NGDC-7. Boulder, CO: National Geophysical Data Center, 34 pp.

Thatcher, C.A., Brock, J.C., Danielson, J.J., Poppenga, S.K., Gesch, D.B., PalaseanuLovejoy, M.E., ... Gibbs, A.E. 2016. Creating a Coastal National Elevation Database (CoNED) for science and conservation applications. J Coast Res. 76(sp1):64-74. https://doi.org/10.2112/ SI76-007.

Toll, R. 2018. An intergovernmental blueprint for community resiliency, The Hampton Roads sea level rise preparedness and resilience intergovernmental pilot project. Mar Technol Soc J. 52(2):(in this issue).

VGIN VITA. 2015. GIS Strategic Plan 20152020. Available at: https://www.vita.virginia. gov/media/vitavirginiagov/integrated-services/ pdf/GIS_Strategic_Plan_Final_Mar19.pdf. (accessed November 1, 2017). 


\section{Appendix A}

Hampton Roads, VA, Sensor Assets and Public Web API URLs for Near-Real Time Water Level Data (http://www.vims. edu/people/loftis_jd/HRVASensorAssets/index.php)

\section{Appendix B}

Coastal Flooding Products Available Near Hampton Roads, VA, from Illuminating the Challenges: Flood Data to Local Action Workshop, September 2016 (https:/wm1693.box.com/s/a8vgidonn4wmhkzx21287n7t3zp8srgl) 